\title{
Some Economics of Seasonal Gas Storage*
}

\author{
Corinne Chaton $^{\dagger} \quad$ Anna Creti ${ }^{\ddagger} \quad$ Bertrand Villeneuve $^{\S}$
}

July 21th 2008

\begin{abstract}
We propose a model of seasonal gas markets which is flexible enough to include supply and demand shocks while also considering exhaustibility. The relative performances of alternative policies based on price caps and associated measures or tariffs are discussed. We illustrate with structural estimates on US data how this theory can be used to give insights into the intertemporal incidence of policy instruments.
\end{abstract}

\section{Introduction}

As energy markets become tenser and dependency on foreign imports increase in most economies, it is a challenging task to draw the picture of the modern gas industry. We analyze in a coherent framework this industry by focusing on the economics of seasonal storage. Our approach is thus a useful complement to the models that focus on other relevant aspects of the gas industry, like transportation and its regulation (e.g. Teece, 1990, Banks, 2007). We then broaden the scope by bringing into the picture gas price shocks, trends as well as public policies.

Storage is the most natural source of flexibility in the gas sector, since consumption, strongly influenced by weather, is seasonal and supply is relatively inflexible. Storing gas thus serves to avoid oversized extraction and transportation infrastructures, as well as to limit excessive price fluctuations.

\footnotetext{
${ }^{*}$ We are grateful to Jean-Christophe Poudou, Saïd Souam and Alban Thomas for their valuable remarks.

${ }^{\dagger}$ Electricité de France R\&D. E-mail: corinne.chaton@edf.fr

¥Università Bocconi and IEFE. E-mail: anna.creti@unibocconi.it

$\S$ Université de Tours, CREST (Paris) and Laboratoire de Finance des Marchés d'Énergie. E-mail: bertrand.villeneuve@ensae.fr
} 
To focus on these economic mechanisms, we investigate the relationship between stored quantities and prices in a model where time is discrete and infinite. Years are split into two seasons, a simplification that is grossly acceptable since we focus on aggregate dynamics of the economy. We characterize the competitive equilibrium and find realistic conditions for storage to be seasonal (stocks are empty each year at the end of winter). Stockpiling in summer and withdrawal in winter is shown to be consistent with random shocks and exhaustibility of natural gas.

Although there would seem to be limited scope for government intervention in a competitive gas sector, public decisions are rarely motivated by pure efficiency considerations. To clarify the effects of different policies, we characterize the best outcome a government can implement to maximize consumers' surplus when gas is mainly imported. The basic novelty of our analysis is that, modeling seasonal storage, we explicitly take into account the intertemporal incidence of policy instruments such as a price cap associated with quantitative restraints, or taxes.

The price cap succeeds in smoothing prices but discourages storage and implies winter rationing. We show that, in theory, this distortion can be attenuated by adopting side measures such as summer rationing. Taxes in fact are a more effective policy instrument to exert monopsony power on foreign producers, as a multiseason scheme spreads the distortions better than a winter price cap. Taxes decrease consumption, domestic production and imports compared to the competitive allocation. Whether storage is discouraged or not depends finely on the relative impact of taxes between the two seasons.

We provide an illustration of our model by estimating and testing it on US data. The US is the largest consumer of natural gas in the world (about a quarter of the total) and also the largest importer (BP Statistical Review, 2007). ${ }^{1}$ This market also offers an interesting perspective on policy intervention: according to the FERC Energy Policy Act of 2005, moderating the recurrence and severity of "boom and bust" cycles while meeting increasing demand at reasonable prices is one of the major challenges facing the US natural gas industry today. Rationing was common in the United States during the 1970s' winters, as a consequence of restrictive regulatory policy on wellhead prices. More recently, several examples of specific policy interventions can be found at the state level in terms of excise taxes or gas price ceilings as emergency measures. ${ }^{2}$ The estimation results show that the optimal price

\footnotetext{
${ }^{1}$ An overview of the US natural gas industry in Appendix A.1 recalls basic facts on the yearly gas cycle and gives orders of magnitude.

${ }^{2}$ Ohio levies a public utility excise tax on natural gas utilities and pipeline companies. Other States, like North Carolina, impose an excise tax on piped natural gas received for
} 
cap is globally (i.e. in terms of social surplus) less distortionary than optimal tariffs, but it is less attractive for residents. The price cap discourages storage, as predicted, and more than tariffs.

The questions about storage are not new. In the theoretical literature, the "supply of storage" models (Kaldor, 1939, Working, 1948, Brennan, 1958) are mainly interested in the role of storage when the economy experiences unexpected shocks. However, very few papers tackle the specific issues of seasonal storage. Brennan (1960) sees it as a mere aspect of general purpose models. Pyatt (1978) considers continuous time stationary demand and supply subject to a fixed seasonal pattern that might not correspond. He shows how storage regulates the rate at which output increases over time. Lowry et al. (1987) analyze the role that storage plays in allocating supplies within the year in the soybean market. The authors characterize competitive speculative storage and in particular estimate the expected price function using computational rational expectations methods, when both demand and production are random.

Our focus on yearly cycles over an infinite horizon is a distinguishing feature from storage models that use high frequency data for price simulations and predictions in a short-medium term time frame (Urìa and Williams, 2007).

A unique approach to some of the issues we address is to be found in Amundsen (1991), who investigates the social optimization problem of three operations: the extraction of natural gas from a reservoir up to its depletion, the supply to the storage unit (where either gas passes through or is stored), the transfer to end-users. Amundsen's model is rich and complex. Dynamics of extraction, inflows/outflows from storage, deliveries to consumers are connected so intricately that policy analysis is practically impossible. However, this issue is of crucial importance.

Public interventions through storage have taken several forms, as it can be argued from different works. One set of models has analyzed the so-called "buffer stocks" that are used by public agencies to stabilize agricultural prices (Waugh, 1944, Oi, 1961, Massel, 1969). In these models storage costs and

final consumption. In emergency situations, gas price ceilings have been evoked, even though in practice these measures can be temporary or not implemented. This was the case, for instance, in California, in 2001, when the Long Beach City Energy Director, considering that residential gas bills would likely have increased by about $34 \%$ compared to the previous year, proposed a ceiling of $\$ 1$ a therm (Bernstein et al., 2002). The decision of the Aloha State to put into effect in August 2005 a new state law slapping a ceiling on gasoline prices pegged to average prices on the mainland, has raised a debate on the surplus enhancing effect of price controls in the oil and gas industries (Committee on Energy and Commerce, 2005). 
management are simply abstracted away. Some trade models (for example, Hueth and Schmitz, 1972, Just et al., 1977, Devadoss, 1992) analyze public market interventions that protect national interests from imported price fluctuations. Welfare gains are computed by comparing the economic situation with and without stocks but storage is not optimized at the decentralized level.

Williams and Wright (1991) have considerably enlarged the analysis of storage in dynamic stochastic models. Unfortunately, the complexity of the underlying dynamic model makes the characterization of the effectiveness and efficiency of public interventions quite messy. Therefore, in the absence of clear-cut explanations, only "rough" quantitative estimates of various welfare effects of alternative government programs are computed numerically. Our stylized model will simplify such evaluations.

In Section 2, we expose the main modeling assumptions. In Section 3, we characterize the competitive equilibrium under mild assumptions. The benchmark model opens the way to a detailed policy analysis in Section 4 . We test the model using US data in Section 5. The estimates enable us to evaluate the impact on storage, prices and welfare of the policies we treated theoretically. The final section concludes. Proofs as well as estimates of the basic model are relegated to the Appendices.

\section{The model}

The section sets up the model and characterizes the equilibrium.

Supply and demand. Six-month periods alternate between summer $S$ and winter $W$. A period is denoted by $y \sigma$ with $y$ for year and $\sigma$ for season. The period that follows $y \sigma$ is $n(y \sigma)$ where $n$ is for next; in particular $n(y S)=$ $y W$ and $n(y W)=(y+1) S$. We also use $n^{m}(y \sigma)$ and $n^{-m}(y \sigma)$, with $m$ a positive integer, to indicate the $m$ th period respectively after and before $y \sigma$.

The strictly decreasing consumption function at period $y \sigma$ is denoted by Cons $_{y \sigma}[\cdot]$. Production at period $y \sigma$ is denoted by $\operatorname{Prod}_{y \sigma}[\cdot]$. Production is non-decreasing with respect to the price. We assume that for all periods $y \sigma$, consumption and production functions cross only once: the corresponding equilibrium price is denoted $p_{y \sigma}^{0}>0$. The difference between summer and winter comes basically from the fact that the equilibrium summer price is lower than the winter price. More precisely: $p_{y W}^{0} \geq p_{y S}^{0}$ and $p_{y W}^{0} \geq p_{(y+1) S}^{0}$, $\forall y$. These natural conditions will directly make seasonal factors important without assuming a purely cyclical repetition year after year. 
Due to storage, prices are not determined by short term equilibria. The price in period $y \sigma$ is denoted $p_{y \sigma}$.

Competitive storage. Storage is assumed to be a competitive activity with constant marginal cost $c$ up to the maximum capacity $K$. The unit storage charge in period $y \sigma$, denoted by $\kappa_{y \sigma}$, equals the marginal cost $c$ if the capacity constraint is slack, otherwise $\kappa_{y \sigma}$ exceeds the marginal cost. The interest rate from one period to the next is $r$.

Total inventories $G_{y \sigma}$, counted at the end of $y \sigma$, cannot be negative. Rational price-taking behavior leaves them null if there are no expected benefits from storing. Those benefits come from capital gains (increase in unit price of gas); costs are the direct rental price of storage ( $\kappa_{y \sigma}$ per unit) and the foregone interest (stored gas does not bear interest). This can be expressed as follows

$$
\frac{p_{n(y \sigma)}}{1+r}<p_{y \sigma}+c \Rightarrow G_{y \sigma}=0 .
$$

An equivalent expression says that there are stocks only if prices follow a precise evolution

$$
G_{y \sigma}>0 \Rightarrow \frac{p_{n(y \sigma)}}{1+r}=p_{y \sigma}+\kappa_{y \sigma} \quad \text { with } \kappa_{y \sigma} \geq c .
$$

To simplify the analysis, we summarize the response of the economy to prices by the aggregate excess supply function

$$
\triangle_{y \sigma}[\cdot] \equiv \operatorname{Prod}_{y \sigma}[\cdot]-\operatorname{Cons}_{y \sigma}[\cdot] .
$$

For each period, conservation of matter imposes that the excess supply in one period (positive or negative) is exactly equal to the stocks variation equation

$$
\triangle_{y \sigma}\left[p_{y \sigma}\right]=G_{y \sigma}-G_{n^{-1}(y \sigma)} .
$$

No bubble. We can easily argue that in any equilibrium with reasonably stable fundamentals, stocks have to revert to zero from time to time. A priori, with endogenous prices and storage, the equilibrium could be a "bubble" in which prices grow unboundedly after a certain period $y \sigma$, following the noarbitrage equation (2)

$$
p_{n^{m+1}(y \sigma)}=(1+r) \cdot\left(p_{n^{m}(y \sigma)}+\kappa_{n^{m}(y \sigma)}\right), \quad \forall m, \text { with } \kappa_{n^{m}(y \sigma)} \geq c .
$$

With this explosion of price, consumption shrinks and production grows period after period, implying ever increasing stocks, which is not credible. To avoid the anomaly and retain only reasonable equilibria, it suffices to impose that (5) is impossible. 
Equilibrium. Absent storage, periods are not linked to each other economically speaking. The equilibrium would be the unique sequence of prices $p_{y \sigma}^{0}$ equalizing consumption and production every period $\left(\triangle_{y \sigma}\left[p_{y \sigma}^{0}\right]=0, \forall y, \sigma\right)$. But if in some period $y \sigma$, prices are such that

$$
\frac{p_{n(y \sigma)}^{0}}{1+r}>p_{y \sigma}^{0}+\kappa_{y \sigma}
$$

then storage creates value and is expected in equilibrium. This is typically the case if the price differential between successive prices is sufficiently high, the interest rate and storage costs are sufficiently low.

Definition 1 (Equilibrium) A competitive equilibrium starts in period $0 S$, with some stocks $G_{0 S}$; it is a sequence of gas prices $p_{y \sigma}$, storage charges $\kappa_{y \sigma}$ and inventory levels $G_{y \sigma} \geq 0$ such that, for all yo after $0 S$

- if $\frac{p_{n(y \sigma)}}{1+r}<p_{y \sigma}+c$ then $G_{y \sigma}=0$;

- if $\frac{p_{n(y \sigma)}}{1+r}=p_{y \sigma}+c$ then $0 \leq G_{y \sigma} \leq K$;

- if $\frac{p_{n(y \sigma)}}{1+r}=p_{y \sigma}+\kappa_{y \sigma}$ with $\kappa_{y \sigma}>c$ then $G_{y \sigma}=K$;

- $\triangle_{y \sigma}\left[p_{y \sigma}\right]=G_{y \sigma}-G_{n^{-1}(y \sigma)}$;

- stocks go to zero every so often (no-bubble condition).

Price-taking behavior of the agents, strictly increasing excess supply functions, linearity of the storage technology, all these hypotheses suffice to ensure that the competitive equilibrium maximizes the total surplus, obtained by adding consumers' and producers' surpluses each period discounted at the interest rate. We retrieve the classical virtue of competition.

\section{Seasonal storage}

After the elimination of bubbles, it remains to be established that the equilibrium patterns are "simple". This theoretical section shows that the alternation between stockpiling in summer and complete utilization of the stock in winter is a robust feature of the model. 


\subsection{Basic pattern}

If the price is $p$ in some period, $N[p] \equiv(1+r)(p+c)$ denotes the price realized the subsequent period if storers decided to store. Consistently, $N^{m}[p]$ denotes the price attained after $m$ seasons of uninterrupted stockholding.

The following condition restricts the rate at which supply and demand (thus excess supply) change over time. It says in particular that if a price $p$ cause additional stockholding, then the price attained after two seasons of uninterrupted stockholding - that is $N^{2}(p)$ - is significantly higher than $p$ and must cause additional stockholding two periods after.

Definition 2 The economy is said to be regular if for all seasons $\sigma$, all years $y$ and all prices $p$

$$
\triangle_{(y+1) \sigma}\left[N^{2}[p]\right] \geq \triangle_{y \sigma}[p]
$$

If the economy's fundamentals are purely cyclical $\left(\triangle_{y \sigma}[\cdot]\right.$ does not change from year to year), then the above condition is satisfied.

The following proposition states that storage in regular economies is dominated by seasonal factors rather than by trends.

Proposition 1 (Seasonal pattern) If the economy is regular, then in any competitive equilibrium, storage becomes seasonal (stocks are empty each year at the end of winter) after a finite number of periods and remains so.

Proof. See Appendix A.2.

If the economy starts with huge reserves, prices start low and increase steadily season after season following the no-arbitrage equation (2). After the reserves have been exhausted once, which is inevitable given the nobubble condition, the residual cycle would consist of stockpiling in summer and depleting reservoirs in winter.

The seasonal cycle means that years are independent of each other. This simplification enables us to characterize the equilibrium for any year $y$. Assume a large $K$ to ensure that $\kappa_{y S}=c$. There are two cases. If $p_{y W}^{0} /(1+r) \leq$ $p_{y S}^{0}+c$ and there are no inventories, for lack of profitability. If $p_{y W}^{0} /(1+r)>$ $p_{y S}^{0}+c$, the two prices $\left(p_{y S}, p_{y W}\right)$ are determined by two fundamental equations: conservation of matter (equation 4), and no-arbitrage condition (equation 2). Storage smooths prices: the summer price increases and the winter price decreases but remains higher. Consequences on consumptions are direct: an decrease in summer and an increase in winter.

Figure 1 illustrates the case of the two-season equilibrium with linear demand, a production function independent of the season (the year index is dropped), and sufficient storage capacity $K .^{3}$ 


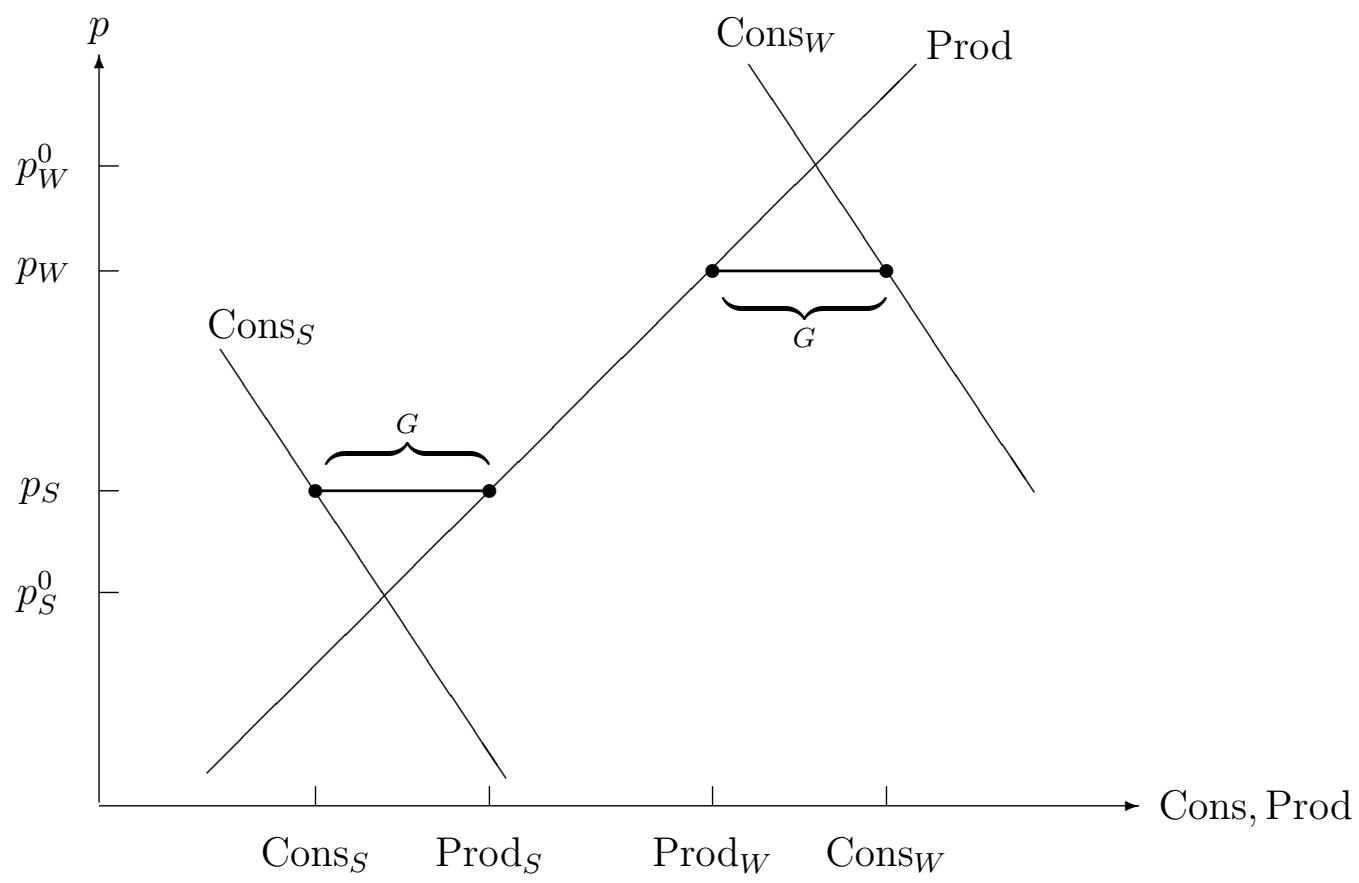

Figure 1: Unconstrained Competitive Storage.

\subsection{Shocks}

The property that stocks are fully used at the end of the winter is generalizable to a stochastic version of the model. Assume that season specific shocks impact the excess supply function (i.e., fundamentally, supply and demand) and that this shock is known only at the beginning of the season. This means simply that decisions made one season before were not informed of the magnitude of the upcoming shock, whereas decisions taken during the season take it into account. Temperature and weather conditions in general are good examples.

The heuristic is the following. Take a deterministic economy as studied in the previous paragraphs and assume conditions are met for a cyclical pattern. If we perturb the model by adding "small" shocks then there is no possible state of the economy in which speculators store at the end of the winter for the coming summer. The question is to define "small".

The first step to show that this approach works is to solve the equilibrium

\footnotetext{
${ }^{3}$ Remark that if $K$ is saturated at the end of the summer, we have one more unknown $\left(\kappa_{y S}\right.$ instead of $c$ ), and one more equation $\left(G_{y S}=K\right)$, which leaves the system solvable. The endogenous storage charge generates a scarcity rent $\kappa_{y S}-c$.
} 
by treating each year separately assuming that each year starts and finishes with empty stocks. This amounts to reasoning as if interyear storage were forbidden. The resulting equilibrium prices are random: the summer price depends on the summer shock (plus expectations as for the winter shock to come), the winter price depends on the summer (through the past storage decisions) and winter shocks. This generates the supports for summer and winter prices. The second step is to search for conditions under which storage from winter to summer is never desirable in any realization of the possible states of nature. It suffices to compare the smallest possible winter price with the expected subsequent summer price. If the former is high enough (or equivalently, if the latter is low enough), then storage is never profitable. This implies that stockout at the end of winters is systematic. The condition to obtain this result is to have shocks of limited magnitude (with respect to the no-storage price range) in both summer and winter.

\subsection{Trends and cycles with exhaustible reserves}

Natural gas is an exhaustible resource: the equilibrium cannot be stationary, except if production and consumption become null. We examine now the implication of this property for a "seasonal" model. We show that the economy crosses three significantly different phases. The intermediate one, which may be very long, exhibits interesting and empirically important cyclical features.

\subsubsection{A simple model}

We assume that finite gas reserves are concentrated at a unique wellhead $\mathrm{H}$. Consumption is concentrated in a unique region $B$ (Burnertips). A pipeline of capacity $Q$ (per period) connects $\mathrm{H}$ and $B$. Marginal extraction cost is $c_{\mathrm{H}}$, while marginal transportation cost along the pipeline is $c_{\mathrm{T}}$ (both $c_{\mathrm{H}}$ and $c_{\mathrm{T}}$ are assumed to be constant and stationary). ${ }^{4}$ Storages are located at $B$. Each period, gas can either be kept in the original field (i.e. not produced) or stored in the consumption region once it has been transported there. The difference between the gas field and storages lies in stockholding costs (zero in the former and $c$ per unit per period in the latter). See Figure 2 for a simple illustration.

We assume that all agents are price-takers and that all arbitrage possibilities (through transportation or storage) are exploited. The price at node $i(=\mathrm{H}, B)$ and period $y \sigma$ is denoted by $p_{y \sigma}^{i}$. The unit profit at $\mathrm{H}$ for period

\footnotetext{
${ }^{4}$ Remark that $Q$ could alternatively be interpreted as the maximum capacity of the production sector.
} 


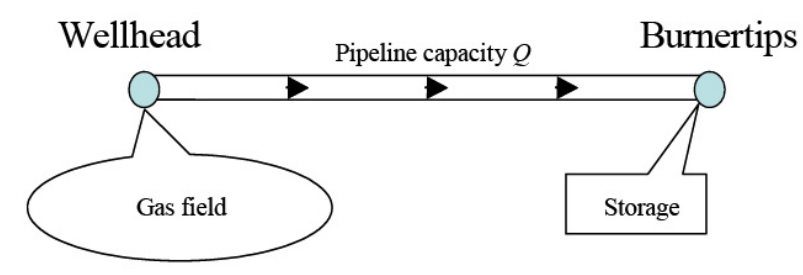

Figure 2: Extraction, storage, burning.

$y \sigma$ is $p_{y \sigma}^{\mathrm{H}}-c_{\mathrm{H}}$, which, according to the Hotelling rule, grows at rate $r$. This implies

$$
\frac{p_{n(y \sigma)}^{\mathrm{H}}}{1+r}-p_{y \sigma}^{\mathrm{H}}=-\frac{r}{1+r} c_{\mathrm{H}}<0 .
$$

The wellhead price grows more slowly than the interest rate.

We consider an economy in which gas demand functions in winter and summer are stationary. Inverse demand functions in summer $S$ and and winter $W$ are denoted by $p_{S}[\cdot]$ and $p_{W}[\cdot]$ respectively. To keep the economically appealing case in which seasonal storage is desirable when imports are maximum (line is congested), we assume that $p_{W}[Q] /(1+r)>p_{S}[Q]+c$.

To simplify matters, we assume that, during the first period, stocks are empty (no domestic gas fields). We describe the situation at "the beginning" (low prices), during the transition (intermediate prices) and at "the end" (high prices). A more realistic description would be a model in which fields are increasingly costly or increasingly remote from the consumption region as depletion goes on. The effects for consumers would remain roughly identical with similar phases.

\subsubsection{Three phases}

Large reserves/Low prices. Demand is high and the pipeline is fully used in both seasons. In the absence of storage, prices would be $p_{y S}^{B}=p_{S}[Q]$ and $p_{y W}^{B}=p_{W}[Q]$. The assumption above on these prices ensures that there is some storage $\widetilde{G}$ taking place, the unique solution to the following no-arbitrage equation

$$
p_{W}[Q+G] /(1+r)=p_{S}[Q-G]+c .
$$

The equilibrium prices are $p_{y S}^{B}=p_{S}[Q-\widetilde{G}]$ and $p_{y W}^{B}=p_{W}[Q+\widetilde{G}]$.

The economy follows a trend at $\mathrm{H}$, but is strictly cyclical at $B$ (seasonal consumer prices and quantities consumed or stored are constant). The total profits (mineral rent plus pipeline congestion rent) are $\left(p_{S}[Q-\widetilde{G}]-c_{\mathrm{H}}-c_{\mathrm{T}}\right) Q$ 
in summer and $\left(p_{W}[Q+\widetilde{G}]-c_{\mathrm{H}}-c_{\mathrm{T}}\right) Q$ in winter. Remark also that this globally constant rent is gradually transferred from the pipeline owners to the reserve owners; indeed, $p_{y \sigma}^{B}$ increases over the years, whereas $p_{y \sigma}^{\mathrm{H}}$ is stable. Over time, the transportation network becomes less and less profitable. Storage is competitive and thus produces no net profit.

Intermediate reserves/Intermediate prices. The line is congested in one season only.

If the pipeline is fully used in winter only, the assumption according to which $p_{W}[Q] /(1+r)+c>p_{S}[Q]$ ensures that some storage will take place. The price in summer is the wellhead price plus transportation charge $c_{\mathrm{T}}$ and the price in winter is driven by the no-arbitrage condition

$$
\begin{aligned}
p_{y S}^{B} & =p_{y S}^{\mathrm{H}}+c_{\mathrm{T}}, \\
p_{y W}^{B} & =(1+r)\left(p_{y S}^{B}+c\right) .
\end{aligned}
$$

This is the normal and realistic situation.

In the case where congestion occurs in summer only, we have

$$
\begin{aligned}
p_{y S}^{B} & >p_{y S}^{\mathrm{H}}+c_{\mathrm{T}}, \\
p_{y W}^{B} & =p_{y W}^{\mathrm{H}}+c_{\mathrm{T}} .
\end{aligned}
$$

By rearranging these two equations, we find

$$
\frac{p_{y W}^{B}}{1+r}-p_{y S}^{B}<-\frac{r}{1+r}\left(c_{\mathrm{H}}+c_{\mathrm{T}}\right)
$$

This precludes storage (the RHS is obviously smaller than $c$ ). Congestion in summer always goes with no storage; this case is therefore quite unrealistic but it cannot be logically excluded without making further assumptions on demand functions.

Low reserves/High prices. The line becomes uncongested in both periods and necessarily $p_{y \sigma}^{B}=p_{y \sigma}^{\mathrm{H}}+c_{\mathrm{T}}$ for each period, i.e.

$$
\frac{p_{n(y \sigma)}^{B}}{1+r}-p_{y \sigma}^{B}=-\frac{r}{1+r}\left(c_{\mathrm{H}}+c_{\mathrm{T}}\right)<0<c .
$$

Prices grow more slowly at $B$ than at $\mathrm{H}$, a fortiori more slowly than the interest rate. This eliminates any incentive for storage and the consumers rely entirely on current imports. Remark that the mineral rent remains now integrally in the hands of the producers. 
The first phase is specially relevant for economies that depend highly on energy imports. Price observed at the local level may well be stationary for a while, even if the world price follows the Hotelling rule. An interesting feature of the second phase is diminishing reliance on storage and dissipation of the pipeline rent.

\section{Policy analysis}

The independence between years guaranteed by Proposition 1 can be exploited to analyze policy within years. Consequently, the year index $y$ will be dropped in the following to make for easier reading. After analyzing basic price caps, we characterize the best outcome a government can implement to maximize consumers' surplus as well as the instruments that can be used.

\subsection{Price cap}

A price cap only forces prices not to exceed a certain value, denoted by $\bar{p}$. Markets are otherwise competitive: economic agents take prices as given, therefore the cap could generate a disequilibrium between supply (production and release from inventories) and demand (consumption).

If $\bar{p}$ is higher than the winter price $p_{W}$ expected in the absence of a ceiling, then it has no effect on the economy. If it is too low, it completely discourages storage since the price dynamics motivating stockpiling in summer is sterilized; this happens if $\bar{p} \leq(1+r) \cdot\left(p_{S}^{0}+c\right)$.

For intermediate values $\left((1+r) \cdot\left(p_{S}^{0}+c\right)<\bar{p}<p_{W}\right)$, we have the economically interesting case where winter demand is larger than supply. We assume in that case that consumption is rationed efficiently (consumers with higher valuations are served first), which simplifies the calculation of the surplus. In equilibrium, prices and stocks are denoted, respectively, by $\bar{p}_{S}, \bar{p}_{W}$ and $\bar{G}$ to show their dependency on the price cap $\bar{p}$.

Proposition 2 For economically relevant price caps, i.e. $(1+r) \cdot\left(p_{S}^{0}+c\right)<$ $\bar{p}<p_{W}$,

1. Storage $\bar{G}$, prices $\bar{p}_{W}=\bar{p}$ and $\bar{p}_{S}=\frac{\bar{p}}{1+r}-c$ decrease as $\bar{p}$ decreases; consumers are rationed in winter;

2. Price caps slightly below the unconstrained competitive winter price $p_{W}$ increase consumers' surplus. 


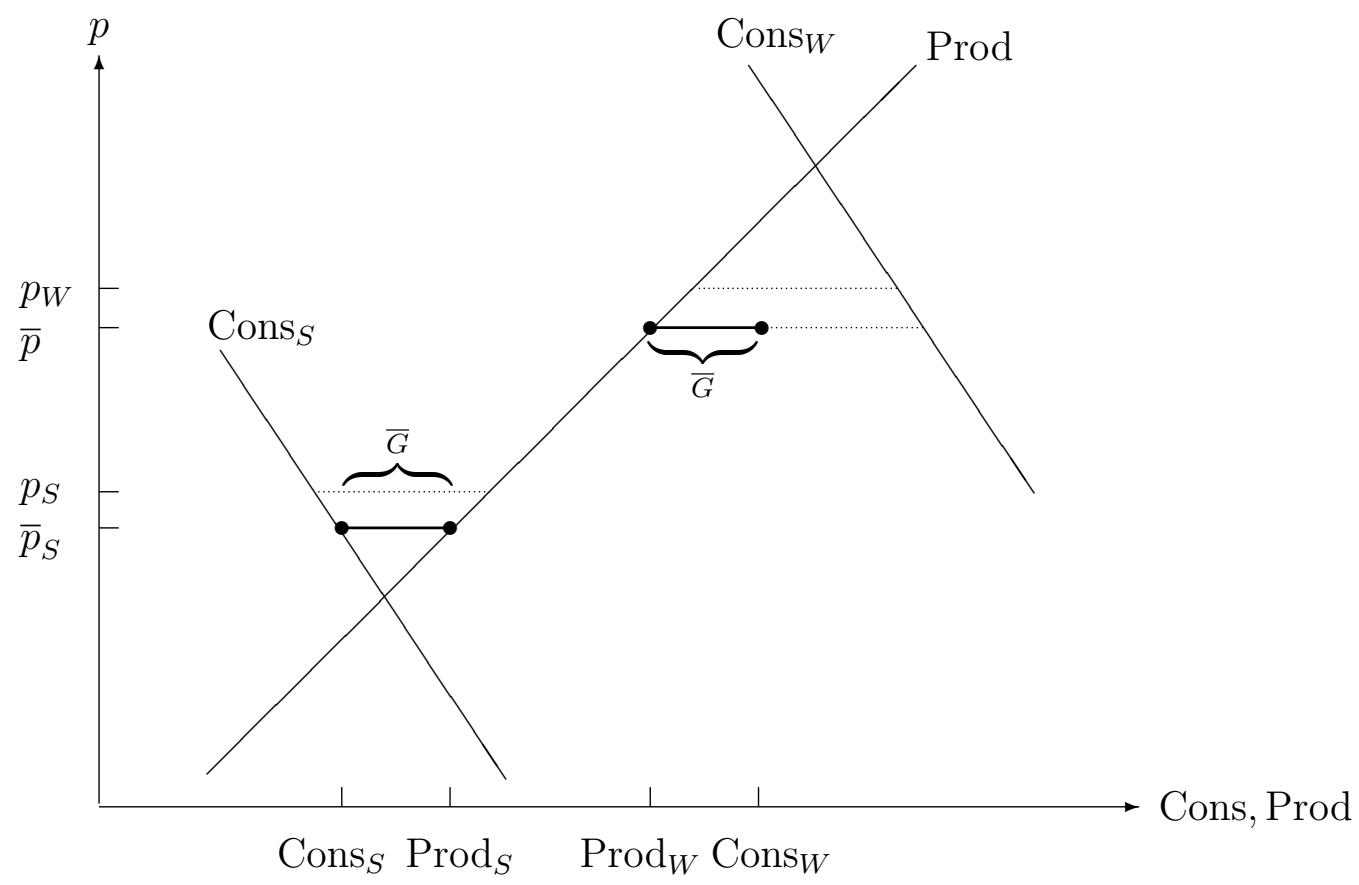

Figure 3: Competitive Storage with Price Ceiling

Proof. See Appendix A.3.

Though price ceilings succeed in reducing prices, price variability remains little affected and storage is discouraged. The latter effect was mentioned in, e.g., MacAvoy and Pindyck (1973) and Wright and Williams (1982b).

If the government in charge of setting the price cap defends the consumers' interest only, then a price cap is desirable. ${ }^{5}$ There are obvious limits to these gains: the deadweight loss is approximately quadratic with respect to the difference between the price cap and the free price, while the price cap generates an approximately linear transfer in favor of the consumers.

As price caps are a way of exerting market power, the result is in line with monopsony pricing theory (here the state "coordinates" consumers through the ceiling), with intertemporal effects due to competitive storage. The practical difficulty is not to go too far once the cycle is fully taken into account. An improvement is to combine the price cap and the inevitable winter rationing with some summer rationing. As the rationing cost is approximately quadratic with respect to the difference between demand and supply, rebalancing rationing between seasons enhances welfare. This raises the issue of

\footnotetext{
${ }^{5}$ Symmetrically to the discouragement effect of the price cap, a price floor higher than the undistorted one will create excess storage and therefore will sacrifice economic efficiency (Helmberger and Weaver, 1977). Producers gain from the government policy, while consumers lose.
} 
finding the optimal policy.

\subsection{Optimal price policy}

To optimize the consumers' or the domestic surplus, we need to be more specific as to fundamentals. The simplest approach is to represent consumers with an intertemporal utility function; the arguments are gas consumption and a separable numéraire that could be seen as labor. The consumers yearly surplus can then be written

$$
U_{S}\left[q_{S}^{C}\right]-m_{S}+\frac{U_{W}\left[q_{W}^{C}\right]-m_{W}}{1+r},
$$

where $U_{S}$ and $U_{W}$ are increasing and concave utility functions, $q_{\sigma}^{C}$ is season $\sigma$ gas consumption and $m_{\sigma}$ is season $\sigma$ expenditure. The year index $y$ is dropped without loss of generality. Domestic production is simply modeled through cost functions $C_{S}^{D}[\cdot]$ and $C_{W}^{D}[\cdot]$; imports are represented with the inverse supply functions $p_{S}^{I}[\cdot]$ and $p_{W}^{I}[\cdot]$ respectively. Storage is assumed to be domestic.

The optimal policy in the interest of the residents (consumers plus domestic producers) can be characterized using the following method: all quantities $\left(q_{S}^{C}\right.$ and $q_{W}^{C}$, domestic productions $q_{S}^{D}$ and $q_{W}^{D}$, and imports $q_{S}^{I}$ and $q_{W}^{I}$ ) are taken as choice variables. Domestic production is accounted for its cost while imports are accounted for the expenditure. The stocks are $q_{S}^{D}+q_{S}^{I}-q_{S}^{C}$. The government solves

$$
\begin{aligned}
\max _{q_{S}^{C}, q_{W}^{C}, q_{S}^{D}, q_{W}^{D}, q_{S}^{I}, q_{W}^{I}} & U_{S}\left[q_{S}^{C}\right]-C_{S}\left[q_{S}^{D}\right]-p_{S}^{I}\left[q_{S}^{I}\right] q_{S}^{I} \\
+ & \frac{U_{W}\left[q_{W}^{C}\right]}{1+r}-\frac{C_{W}\left[q_{W}^{D}\right]}{1+r}-\frac{p_{W}^{I}\left[q_{W}^{I}\right] q_{W}^{I}}{1+r} \\
& -c\left(q_{S}^{D}+q_{S}^{I}-q_{S}^{C}\right)
\end{aligned}
$$

such that $q_{S}^{D}+q_{S}^{I}+q_{W}^{D}+q_{W}^{I} \geq q_{S}^{C}+q_{W}^{C}$, $q_{S}^{D}+q_{S}^{I} \geq q_{S}^{C}$.

The first constraint states that total consumption must not exceed total production and imports. The second one states that stocks are positive.

We only discuss the case of strictly positive storage at the end of the summer (the last constraint is slack). The necessary and sufficient conditions, 
after elimination of the Lagrange multipliers, are

$$
\begin{aligned}
U_{S}^{\prime}\left[q_{S}^{C}\right] & =C_{S}^{\prime}\left[q_{S}^{D}\right], \\
U_{W}^{\prime}\left[q_{W}^{C}\right] & =C_{W}^{\prime}\left[q_{W}^{D}\right], \\
U_{S}^{\prime}\left[q_{S}^{C}\right]+c & =\frac{U_{W}^{\prime}\left[q_{W}^{C}\right]}{1+r}, \\
U_{S}^{\prime}\left[q_{S}^{C}\right] & =p_{S}^{I}\left[q_{S}^{I}\right]+p_{S}^{I \prime}\left[q_{S}^{I}\right] \cdot q_{S}^{I}, \\
U_{W}^{\prime}\left[q_{W}^{C}\right] & =p_{W}^{I}\left[q_{S}^{I}\right]+p_{W}^{I \prime}\left[q_{W}^{I}\right] \cdot q_{W}^{I}, \\
q_{S}^{D}+q_{S}^{I}+q_{W}^{D}+q_{W}^{I} & =q_{S}^{C}+q_{W}^{C} .
\end{aligned}
$$

The interpretation of the first three equations straightforward: equations (17) and (18) only require that consumers' marginal utilities equal domestic marginal costs; (19) consumers' intertemporal MRS should satisfy the noarbitrage equation (domestic storage must not be distorted). Equations (20) and (21) show how the government should exert its monopsony power on foreign producers.

Proposition 3 Compared to the competitive allocation, the best allocation for consumers is such that consumptions, domestic productions and imports at each period decrease. The benefits come from lower import prices each period.

Proof. See Appendix A.4.

Storage may be greater with the optimal policy than under laissez-faire. This possibility was existent with the less efficient price cap policy. Assume for example that winter demand is very inelastic compared to summer demand. Since production is reduced in both periods, winter demand can be met only by discouraging summer demand. Given the elasticities, this is the less distortionary choice; accordingly, one has to increase the stored quantity of gas.

\subsection{Implementation}

The allocation maximizing domestic surplus can be sustained with tariffs on imports each season (denoted by $\tau_{S}$ and $\tau_{W}$ ) and competitive markets. No intervention is required in the domestic market (storage sector included): consumption is not rationed and domestic storers simply arbitrage. Each season, the import price plus the tariff equals the domestic price. The domestic prices are simply denoted $p_{S}$ and $p_{W}$.

This gives: 


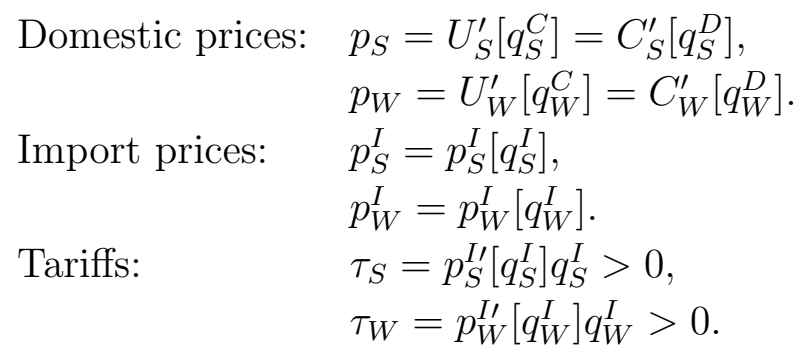

The interpretation of price policy in terms of taxation unifies the view on the various policies that have been or could be observed or proposed. We disagree with Wright and Williams (1982b) who write that "a price ceiling can crudely substitute for an optimal tariff, if this latter cannot be implemented." Indeed, a price cap supposes controls and rationing, as we saw earlier; but efficient rationing is extremely demanding in terms of information because it requires knowledge of the private marginal valuations of all the consumers whereas the tariff merely requires uniform application. The government can implement the same allocation just by imposing a well calculated tax. ${ }^{6}$

Above all, optimal tariffs implement an optimally balanced "rationing" (or preferably demand containment) between summer and winter, whereas the version we discussed in 4.1 concentrates the effort on winter, which is suboptimal. Moreover, as it is typical of second best policy, this primary distortion must be mitigated by other distortions. The government may wish to compensate the undesirable effects of the basic price cap (discouraging storage) with subsidies on storage (or, if one prefers, subsidies across periods). Tariffs are simpler.

\section{Applications}

The liberalization of the US gas market is now sufficiently well established (Hirschhausen, 2007) to provide data on prices and quantities that can be used to estimate structural parameters and test a number of our model's predictions (Appendix A.5). Though the results are satisfactory in many ways, the accuracy of the estimates drawn from the aggregate approach is insufficient to formulate firm predictions. With this reservation in mind,

\footnotetext{
${ }^{6}$ Wright and Williams (1982b) assumed that consumption is rationed by marketable coupons distributed to consumers. Therefore, a kind of "secondary spot markets" must exist for rationing to be efficient (the least costly in terms of welfare). This idea goes against the principle of a price cap, since some transactions are indeed made above the ceiling. In all events, such markets seem to be quite unlikely to emerge at the final consumption level.
} 
we propose a comparative simulation of the impact of various price policies discussed in Section 4.

Evaluation of the welfare effects of price policies. To focus on price policies, we reason on the average year (sample average temperature, GDP, number of wells). Linear demand and supply functions are integrated to give linear-quadratic utility and cost functions. We compare three scenarios using the structural parameters estimated under the assumption that markets are competitive:

1. Pure competition.

2. The optimal price cap for residents (consumers and domestic producers) with winter efficient rationing (see Subsection 4.1).

3. The residents' optimum: tariffs only, no rationing (see Subsection 4.2). We calculate optimal $\tau_{S}$ and and associated equilibrium prices and quantities (see Subsection 4.3).

We start by estimating directly the structural equations of the model under a linear specification using the 3SLS. For each year, the equilibrium involves four equations: excess supplies in summer and in winter, price arbitrage and annual balance. The observed variables for season $y \sigma$ are the variation of the stock, the average gas price, GDP and average temperature. Appendix A.5 describes our procedure and results. The tests of theory based linear restrictions and signs are passed.

The four core equations only require stock variations. To evaluate welfare, we must complement them with some structural estimates of demand and supply. In principle estimating precisely demand and supply would require a more comprehensive dynamic theory and this route would be very demanding in terms of data. We have limited ourselves to a very summary model. This gives us a first complete set of parameters to perform comparisons such as those exposed in Table 1. See Appendix A.6.

The total maximum surplus is set by convention to 0 in Table $1 ;^{7}$ other surpluses are given as differences with the maximum. The optimal price cap is overall less distortionary than optimal tariffs; the latter are nevertheless, by definition, more attractive for residents. The optimal tariffs are very large (about $\$ 7$ per MMcf) and do more than halve the import price. This effect is due to the relative inflexibility of imports. The price cap discourages storage, as predicted, and more than tariffs, whose effect is ambiguous in theory.

\footnotetext{
${ }^{7}$ The value found by integration of the demand and supply functions is $\mathrm{B} \$ 6.21$. However this calculation involves extrapolating the functions well beyond the sample.
} 


\begin{tabular}{lrrr}
\hline \hline Scenario & Perfect comp. & Opt. price cap & Opt. tariffs \\
\hline \hline Total surp./year & 0.00 & -1.06 & -1.84 \\
Dom. surp./year & -12.70 & -11.50 & -10.40 \\
Stocks $\left(10^{6}\right)$ & 1.65 & 1.47 & 1.60 \\
\hline Summer & & & \\
Import price & 2.49 & 1.29 & 1.23 \\
Domestic price & 2.49 & 1.29 & 7.51 \\
Tariff & 0.00 & 0.00 & 6.28 \\
\hline Winter & & & \\
Import price & 2.56 & 1.60 & 0.91 \\
Domestic price & 2.56 & 1.60 & 8.08 \\
Tariff & 0.00 & 0.00 & 7.16 \\
\hline \multicolumn{2}{r}{ Table 1. Comparison of three price policies. } \\
\multicolumn{2}{c}{ Quantities in MMcf, prices in $\$$ /MMcf, surpluses in $\mathrm{M} \$}$.
\end{tabular}

A limit to this exercise is that, in accordance with the estimation results, the optimal policy should be conditional on observables like temperature or GDP. More importantly, though the elasticity of imports seems low and thus "justifies" high tariffs, in the long run elasticity, through investment by producers to deliver gas towards more profitable regions, is certainly much greater. The extent of US market power over external providers is also hard to measure. Obviously, the NAFTA prevents any such attempts towards Canadian imports, which nevertheless leaves some leeway for other imports. In any case, the modest extra surplus calculated (in absolute value) could be seen to be upper bounds of the potential benefits. ${ }^{8}$

\section{Conclusion}

The model enabled us to expose a comprehensive view of seasonal natural gas markets. Economies are neither stationary nor purely cyclical. One of our insights is the description of a yearly pattern which is preserved one considers moderate shocks and the exhaustibility of this natural resource. This flexibility enables us to directly formulate our theory in a 4-equation structural model. The estimates based on the US data over 1986-2005 are consistent with a number of theoretical restrictions. The potential surplus gains that the country could achieve are calculated.

\footnotetext{
${ }^{8}$ The interplay between tariffs and price cap was addressed by Wright and Williams (1982), who analyze public policies as a response to an oil supply disruption due to random shocks. However, in the Wright-Williams model, the relative effects of the two price policies, namely the price cap and the import tariffs, are difficult to disentangle as embedded in a very complex dynamic game, with government and the private sector interacting strategically.
} 
Our analysis can be used as a building block of a model where one considers regulatory issues such as access to storage or transportation charges. If the storage capacity is saturated at the end of the summer, the endogenous storage charge generates a scarcity rent. Under competition, allowing usage rights with regulated storage prices or leaving prices unregulated only changes the allocation of the rent, since the prices and quantities exchanged and stored are unaffected. The rent is simply left to those who detain the right to store. Both usage rights with regulated storage prices and unregulated prices lead to the social optimum in which the scarcity rent is the marginal welfare loss due to the constraint. This equivalence is only true in the short run; in the long run investment becomes a serious issue. For regulators, the balance between preserving incentives to invest (rents) and fighting market power requires information on the long run marginal cost, whose evaluation is enormously complicated by the huge heterogeneity of possible sites (location, geological characteristics). Though rents are not per se proofs of noncompetitive behavior, the regulator must be able to distinguish a case of true scarcity from an abuse of market power via voluntary restriction of supply. In this respect, the caution of FERC in allowing gas companies to use market-based rates for storage access instead of regulated tariffs, is understandable. ${ }^{9}$

\section{References}

[1] Amundsen, Erik Schroder (1991): "Seasonal Fluctuations of Demand and Optimal Inventories of a Non-renewable Resource Such as Natural Gas," Resources and Energy, 13, 285-306.

[2] Banks, Ferdinand E. (2007): "The Political Economy of World Energy: An Introductory Textbook," World Scientific.

[3] Balestra, Pietro and Marc Nerlove (1966): "Pooling Cross Section and Time Series Data in the Estimation of a Dynamic Model: The Demand for Natural Gas," Econometrica, 34, 585-612.

\footnotetext{
${ }^{9}$ FERC Order 636 opens access to gas storage at regulated prices that comprise a fixed capacity charge (reservation or booking fee) and a commodity charge (according to usage). Market-based tariffs can be applied where sufficient competition between facilities is demonstrated. To obtain market-based prices, large pipeline companies have to argue that industry restructuring and network interconnections have effectively broadened the market for storage beyond some narrow geographic area where that company predominates, and that prospective storage customers actually have many good alternatives.
} 
[4] Bernstein, Mark, Paul Holtberg and David Santana-Ortiz (2002): "Implications and Policy Options of California's Reliance on Natural Gas," RAND Monograph Report, available at http://www.rand.org.

[5] Brennan, Michael J. (1958): "The Supply of Storage," American Economic Review, $48,50-72$.

[6] Brennan, Michael J. (1960): "A note on Seasonal Inventories: Reply," Econometrica, 28, 921-922.

[7] BP Statistical Review (2007), available at http://www.bp.com.

[8] Committee on Energy and Commerce (2005): Hearing to Examine Hurricane Katrina's Impact on U.S. Energy Supply, available at energycommerce.house.gov/108/Hearings.

[9] Devadoss, Steven (1992): "Market Interventions, International Price Stabilization, and Welfare Implications," American Journal of Agricultural Economics, 74, 281290.

[10] EIA (2006): "U.S. Underground Natural Gas Storage Developments: 1998-2005."

[11] Helmberger, Peter and Rob Weaver (1977): "Welfare Implications of Commodity Storage under Uncertainty," American Journal of Agricultural Economics, 59, 639651.

[12] Hirschhausen, Christian von (2008): "Infrastructure, Regulation, Investment and Security of Supply: A Case Study of the Restructured US Natural Gas Market," Utilities Policy, 16, 1-10.

[13] Hotelling, Harold (1931): "The Economics of Exhaustible Resources," Journal of Political Economy, 39, 137-175.

[14] Hueth, Darrell and Andrew Schmitz (1972): "International Trade and Final Goods: Some Welfare Implications of Destabilized Prices," Quarterly Journal of Economics, $86,351-365$.

[15] Just, Richard E., Ernst Lutz, Andrew Schmitz and Stephen Turnovsky (1977): "The Distribution of Welfare gains from International Price Stabilization under Distortions," American Journal of Agricultural Economics, 59, 652-661.

[16] Kaldor, Nicholas (1939): "Speculation and Economic Activity," Review of Economic Studies, 7, 1-27. 
[17] Lowry, Mark, Joseph Glauber, Mario Miranda and Peter Helmberger (1987): "Pricing and Storage of Field Crops: A Quarterly Model Applied to Soybeans," American Journal of Agricultural Economics, 9, 740-749.

[18] MacAvoy, Paul W. and Robert S. Pindyck (1973): "Alternative regulatory Policies for Dealing with the Natural Gas Shortage," Bell Journal of Economics and Management Science, 4, 454-498.

[19] Massel, Benton F. (1961): "Price Stabilization and Welfare," Quarterly Journal of Economics, 83, 284-298.

[20] Modjtahedi, Bagher and Nahid Movassagh (2005): "Natural-gas Futures: Bias, Predictive Performance, and the Theory of Storage," Energy Economics, 27, 617-637.

[21] Oi, Walter (1961): "The Desirability of Price Instability Under Perfect Competition," Econometrica, 29, 58-64.

[22] Pyatt, Graham (1978) "Marginal Costs, Prices and Storage," Economic Journal, 88, 749-762.

[23] Uría, Rocío and Jeffrey Williams (2007): "The Supply of Storage for Natural Gas in California," The Energy Journal, 28, 31-50.

[24] Teece, David J. (1990): "Structure and organization in the Natural Gas Industry," The Energy Journal, 11, 1-35.

[25] Waugh, Frederic V. (1944): "Does the Consumer Benefit from price Instability?," Quarterly Journal of Economics, 53, 602-614.

[26] Williams, Jeffrey C. and Brian D. Wright (1991): Storage and Commodity Markets, Cambridge University Press.

[27] Wilson, Robert (1989): "Efficient and Competitive Rationing," Econometrica, 57, $1-40$.

[28] Working, Holbrook (1948): "Theory of the Inverse Carrying Charge in Futures Markets," Journal of Farm Economics, 30, 1-28.

[29] Wright, Brian D. and Jeffrey C. Williams (1982): "The Roles of Public and Private Storage in Managing Oil Import Disruptions," Bell Journal of Economics, 13, 341353. 


\section{A Appendices}

\section{A.1 The US gas cycle}

Weather is the primary driver of gas consumption. Because of winter heating, the seasonal pattern of gas deliveries is particularly striking in the residential and commercial sectors. Due to power-generation demand for summer cooling, the electric utilities' consumption is counter-cyclical (3.4 times higher in July and August than in January and February). Nevertheless, the overall seasonal pattern is not offset: the yearly cycle alternates between winter peaks and summer troughs. This is illustrated in Figure 4.

In contrast, extraction from gas wells as well as imports are practically flat (see Figure 5). A smooth production is motivated by cost-efficiency arguments driven by geological considerations. ${ }^{10}$ In addition, production and transportation are highly capitalistic and complementary; the economic optimum requires maximum utilization of the infrastructure and the profitability of the investment is typically secured by long term contracts with limited flexibility. Imports into the United States - almost entirely from Canada - show slightly more of a seasonal pattern than US production, largely because of the extensive use of Canadian upstream storage. The US gas industry is highly diversified with no single dominant company. According to the Natural gas Association, there are about 8,000 gas producers, ranging from small operations to major international oil companies. The five largest producers (BP, ExxonMobil, Chevron-Unocal, Devon Energy, ConocoPhillips, Chesapeake Energy) account for around $25 \%$ of total US output.

Storage plays a key role in balancing seasonal and short-term loads (compare total consumption in Figure 4 with net withdrawals in Figure 5). Natural gas, unlike many other commodities, requires specialized facilities. There are several types of storage: depleted gas or oil fields, aquifers, salt caverns, liquefied natural gas (LNG) tanks. Pipelines can also be used for balancing the transmission flows in order to keep gas pressure within design parameters. Each type has its own economic and physical characteristics. In general, storage facilities are classified according to flexibility (high or low withdrawal and injection rates). The two main classes are high deliverability sites (salt cavern reservoirs and LNG storages) and seasonal supply reservoirs (depleted fields and aquifers). Most existing gas storage in the United States is in depleted natural gas or oil fields that are close to consumption centers. Seasonal supply reservoirs are usually drawn down during the heating season (about 150 days from November to March) and filled during the non-heating season

\footnotetext{
${ }^{10}$ For example, excess withdrawal of gas can submerge the wells with liquids (water, oil), causing interruption of the gas flow.
} 


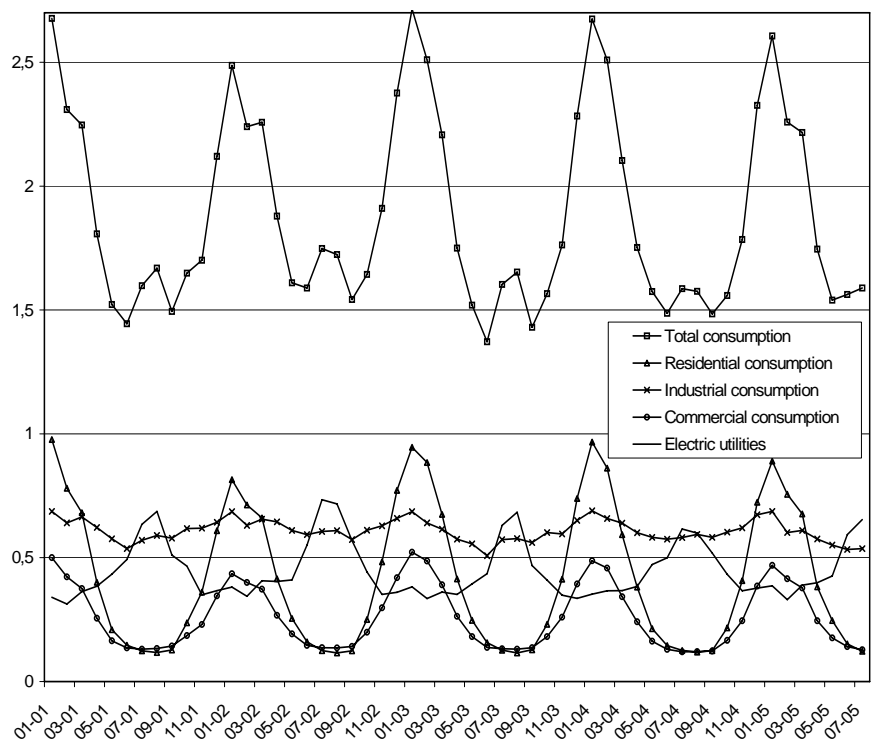

Figure 4: Gas consumption (total and by end use) (Tcf). Source: EIA.

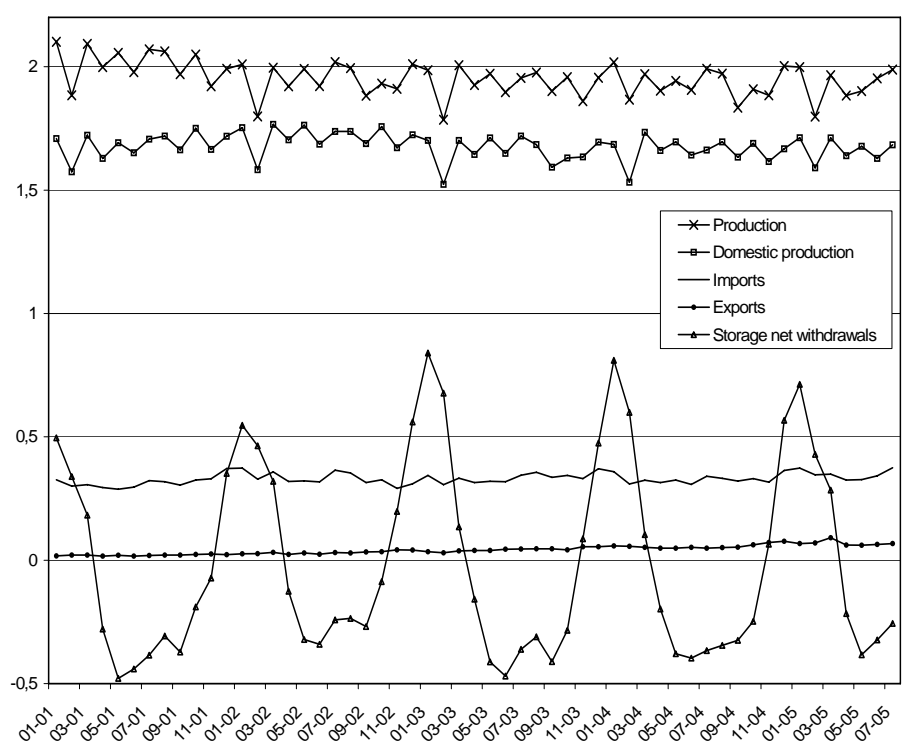

Figure 5: Withdrawals from gas wells and imports (Tcf). Source: EIA. 
(about 210 days from April through October). High deliverability sites can be rapidly drawn down (in 20 days or less) and refilled (in 40 days or less) in order to respond to less expectable peak demands or system load balancing.

In 2005, the US industry had the capability to store approximately 8.2 trillion cubic feet (Tcf) of natural gas in about 391 storage sites around the country, mostly in depleted gas or oil fields. Working gas capacity makes up slightly less than $50 \%$ of the total. The rest goes to the base (or cushion) gas, i.e. the permanent volume of gas in a storage reservoir necessary to maintain adequate pressure and deliverability rates during the withdrawal season. In 2005, the gas withdrawn from storage to end use was 3.047 Tcf, which represents $13.2 \%$ of total gas supplies.

At the close of 2005, 394 underground natural gas storage facilities were operational in the US although 37 were marginal operations that reported little or no activity during the year. Between 1998 and 2005, 42 facilities were abandoned as uneconomic or defective, representing a loss of 223 billion cubic feet (Bcf) in total capacity, while 26 new sites, accounting for $212 \mathrm{Bcf}$ of new capacity, were placed in operation. Yet, as abandoned capacity was always compensated for with new storage field development and the completion of several storage expansion projects, working gas capacity and design-day withdrawal capability (deliverability), the two prime measures of storage utility in today's natural gas storage market, grew steadily and substantially. By 2008, more than 73 underground natural gas storage projects are expected to be undertaken: they have the potential to add as much as 0.346 Tcf to existing working gas capacity (EIA, 2006). New storage sites are mainly salt caverns.

In recent years, the price of natural gas has followed an upward slope to reach unprecedented levels. The development of new production capacity is lagging behind growth in demand, which is also exacerbated by the use of gas for electric power production. Because of the existence of a significant amount of short-term fuel-switching capability in industry and power generation, interfuel competition plays a major role in day-to-day price setting. This demand-side flexibility limits the seasonal volatility of spot prices: in the Northeast and Mid-Atlantic, prices are effectively capped by prevailing heavy-fuel-oil price levels in the winter, when oil typically replaces gas in power generation and in some industrial uses. The ability of power generators to burn coal in the South effectively sets a ceiling price for gas in the summer. The sustained tension on the market results in large spikes when the temperature reaches unusually low levels in winter or unusually high levels in summer. Accidents like the breakdown in 2001 of the El Paso pipeline connecting California to Mexico or natural disasters like Hurricane Katrina in 2005 had similar effects. In 2006, the prices have returned to levels closer 


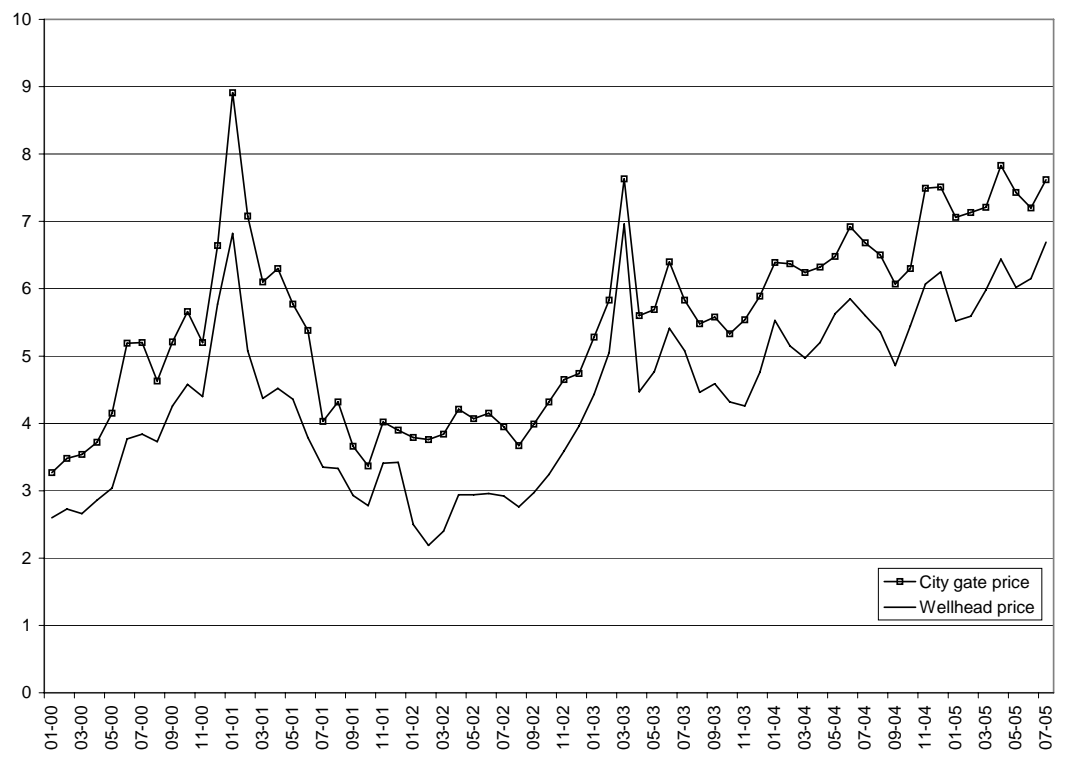

Figure 6: Monthly natural gas price (\$/Mcf). Source: EIA.

to historical average.

In this context, in contrast to previous decades, the seasonality of the price is hardly visible in Figure 6. However, over the last twenty years, the average price over the winter is significantly higher than the average price during the previous summer.

\section{A.2 Proof of Proposition 1}

The no-bubble condition imposes that the stocks become necessarily null in finite time. We show by contradiction that from then on, stockholding remains seasonal (holding stock two or more successive periods is impossible).

Suppose that there is an integer $m \geq 3$ such that stocks are null at the end of $y \sigma$, strictly positive at the end of the periods $n^{j}(y \sigma)$ for $1 \leq j<m$, and null at the end of $n^{m}(y \sigma)$. The stock at the end of period $n^{j}(y \sigma)$ for $j \leq m$ is

$$
G_{n^{j}(y \sigma)}=\sum_{i=1}^{j} \Delta_{n^{i}(y \sigma)}\left[N^{i}\left[p_{y \sigma}\right]\right],
$$

Given that the economy is regular (see definition 2), for all $j$ such that 
$3 \leq j \leq m$

$$
G_{n^{j}(y \sigma)}-G_{n^{2}(y \sigma)}=\sum_{i=3}^{j} \Delta_{n^{i}(y \sigma)}\left[N^{i}\left[p_{y \sigma}\right]\right]>\sum_{i=1}^{j-2} \Delta_{n^{i}(y \sigma)}\left[N^{i}\left[p_{y \sigma}\right]\right]=G_{n^{j-2}(y \sigma)} .
$$

This equation displays a contradiction for $j=m$ : the LHS is negative, while the RHS is positive.

\section{A.3 Proof of Proposition 2}

1. The parallel evolution of the two prices $\bar{p}_{S}$ and $\bar{p}_{W}$ is due to the noarbitrage equation $\left(\frac{\bar{p}_{W}}{1+r}=\bar{p}_{S}+c\right)$ satisfied whenever storage is positive, and to the fact that the constraint binds during peaks: $\bar{p}_{W}=\bar{p}$. To see that storage is discouraged, observe that demand during summer increases whereas production decreases (as current price is decreased). This immediately implies that in winter demand exceeds supply and consumers are rationed.

2. We start from the unconstrained competitive equilibrium. Let us choose $\bar{p}=p_{W}-d p$, with small $d p>0$. We get $\bar{p}_{W}=\bar{p}$ and $\bar{p}_{S}=p_{S}-\frac{d p}{1+r}$. The impact on the consumer's surplus during summer is positive and of first order with respect to $d p$ since they only benefit from the lower price. During winter, on the one hand they benefit from lower prices (first-order effect), but on the other hand, demand is increased (first-order) while supply is decreased (negative first-order effects on production and storage). This rationing only provokes second-order effects on winter surplus, therefore the benefits dominate the loss for small $d p$.

\section{A.4 Proof of Proposition 3}

Equation (19) holds in the competitive and the monopsony allocations, implying that $q_{S}^{C}$ and $q_{W}^{C}$ are both higher or lower in the latter. We show by contradiction that they are lower. Assume that $q_{S}^{C}$ and $q_{W}^{C}$ are higher. The LHS of equations (20) and (21) decrease, meaning that $q_{S}^{I}$ and $q_{W}^{I}$ decrease. Similarly, equations (17) and (18) imply that $q_{S}^{D}$ and $q_{W}^{D}$ also decrease. This contradicts equation (22).

Remark that $G=q_{S}^{D}+q_{S}^{I}-q_{S}^{C}$. Depending on which of production and consumption in summer is most impacted by the government policy, $G$ increases or decreases with respect to the competitive benchmark. One can easily verify with a linear version of the model that both cases are possible. 


\section{A.5 Estimation of the model}

The econometric specification is based on the stochastic model discussed in Section 3.2. The empirical counterpart of the model requires the arguably exogenous controls $\mathbf{Z}_{y S}=\left(T_{y S} Y_{y S}\right)^{\prime}$ and $\mathbf{Z}_{y W}=\left(T_{y W} Y_{y W}\right)^{\prime}$ (season average temperature and GDP). ${ }^{11}$

The observed variables for season $y \sigma$ are therefore

$$
\begin{aligned}
& \Delta_{y \sigma}: \text { variation of the stock; } \\
& p_{y \sigma}: \text { average gas price; } \\
& Y_{y \sigma}: \text { GDP; } \\
& T_{y \sigma}: \text { average temperature. }
\end{aligned}
$$

For each year, the four equilibrium equations are:

$$
\begin{aligned}
\Delta_{y S} & =\beta_{1}^{0}+\beta_{1 p} p_{y S}+\left(\beta_{1 T} \beta_{1 Y}\right) \mathbf{Z}_{y S}+\varepsilon_{y 1} \\
\Delta_{y W} & =\beta_{2}^{0}+\beta_{2 p} p_{y W}+\left(\beta_{2 T} \beta_{2 Y}\right) \mathbf{Z}_{y W}+\varepsilon_{y 2} \\
E p_{y W} & =\beta_{3}^{0}+\beta_{3 p} p_{y S} \\
\Delta_{y W} & =\beta_{4}^{0}+\beta_{4 \Delta} \Delta_{y S}+\varepsilon_{y 4}
\end{aligned}
$$

All shocks have distributions with zero mean. Shocks $\varepsilon_{y 1}$ and $\varepsilon_{y 2}$ are unexpected random shifts in the excess supply functions (thus they can originate in demand or supply) that are observable by economic agents when they make their production or consumption decisions; as for $\varepsilon_{y 4}$, see Tests 1 and 2 below.

We test the following restrictions:

1. $\beta_{4}^{0}=0$ and $\beta_{4 \Delta}=-1$ : total annual excess supply is null on average.

2. $\Delta_{y S}+\Delta_{y W}$ is not correlated with $\Delta_{(y+1) S}$ : no catch-up, weak interannual effects.

3. $\beta_{1 p} \geq 0$ and $\beta_{2 p} \geq 0$ : higher current prices increase excess supply.

\footnotetext{
${ }^{11}$ Also notice that underground storage capacity is not included in the estimation (e.g. equation 26), as data on storage capacity are only available on a monthly basis as from 1993, whereas our dataset covers April 1986 to March 2005, thus resulting in a lack of information for almost one third of the period considered. Moreover, those data show little variability. From March 1993 to March 2005, underground storage capacity increase amounts to $.03 \%$ only. Finally, there is no empirical evidence of saturation (see Section A.1).
} 
4. $\beta_{1 T} \leq 0$ and $\beta_{2 T} \geq 0$ : higher temperatures in summer decrease excess supply (air-conditioning causes higher demand by electric utilities), and higher temperatures in winter increase excess supply (less heating).

5. $\beta_{1 Y} \leq 0$ and $\beta_{2 Y} \leq 0$ : GDP essentially affects demand and thus must impact excess supply negatively.

6. $r \geq 1$ and $c \geq 0$ : using equation (27), we can estimate $r$ as $\widehat{\beta}_{3 p}-1$ and $c$ as $\widehat{\beta}_{3}^{0} / \widehat{\beta}_{3 p}$.

The first two tests challenge our annual approach; the others question standard economic intuition.

A "year" $y$ is composed of two six-month periods and starts with the "summer" (accumulation period) and finishes with the "winter" (drainage period). Using monthly data, we calculated the two consecutive six-month periods that maximize the variability of the stock variation (in other terms that smooth the cycle the least possible) over the sample. The best aggregates we find are 2nd and 3rd quarters for the summer, 4th quarter and 1st quarter of the subsequent year for the winter. Price and temperature averages as well as GDP are calculated for the same periods.

A more complete dynamic analysis of the yearly cycle using original monthly data would be inextricable (in particular, identification problems due to the multiplication of seasonal, i.e. month-specific, effects). Still, the simplicity argument apart, one may question the validity of the proposed time aggregation. Remark that if $p_{S}^{i}$ is the gas price for the $i$ th summer month $(i=1, \ldots, 6)$, and if $r$ and $c$ are, respectively, the opportunity cost of capital and the carrying costs over six months, then, due to continued storage, arbitrage predicts that the price in the $i$ th winter month $p_{W}^{i}$ equals $(1+r)\left(p_{S}^{i}+c\right)$. The six equations that we obtain as $i$ varies can be summed up and divided by six to yield $p_{W}=(1+r)\left(p_{S}+c\right)$, in which the prices are the season averages in the considered year. Moreover, if we assume that, each month, excess supply depends linearly on the current price, the current temperature and the current GDP, then the linear specification of excess demand is also preserved by time aggregation.

The dataset covers April 1986 (year in which deregulation started) to March 2005. Table 2 presents descriptive statistics and sources.

Descriptive statistics. We used the monthly data published by the EIA, aggregated into two seasons per 12-month period from April 1986 to March 2005. Temperature data are from the National Climatic Data service (US Department of Commerce), whereas GDP quarterly data are obtained from the Bureau of Economic Analysis (US Department of Commerce). 


\begin{tabular}{llcccc}
\hline \hline Variable & Unit & Mean & Std. Dev. & Min. & Max. \\
\hline \hline GDP $_{S}$ & $\mathrm{~B} \$$ & 8313 & 1439 & 6262 & 10846 \\
$\mathrm{GDP}_{W}$ & $\mathrm{~B} \$$ & 8317 & 1436 & 6265 & 10838 \\
$\mathrm{Wells}$ & $\#$ & 307129.7 & 49949.19 & 241527 & 401480 \\
$T_{S}$ & ${ }^{\circ} \mathrm{F}$ & 62.77842 & .6637795 & 61.57 & 63.88 \\
$T_{W}$ & ${ }^{\circ} \mathrm{F}$ & 44.41 & .145406 & 41.97 & 46.71 \\
$\Delta_{S}$ & MMcf & 1638388 & 325292.7 & 1160000 & 2262996 \\
$\Delta_{W}$ & MMcf & -1649048 & 294352.6 & -2323528 & -1163000 \\
Dom. prod. $S$ & MMcf & 9331938 & 621662 & 7970839 & $1.01 \times 10^{7}$ \\
Dom. prod. $W$ & MMcf & 9600006 & 303795 & 8898230 & $1.01 \times 10^{7}$ \\
Net imp. $S$ & MMcf & 1282275 & 453669 & 469932 & 1930174 \\
Net imp. $W$ & MMcf & 1164139 & 505577 & 261408 & 1819766 \\
$p_{S}$ & $\$ /$ Mcf & 2.46 & 1.13 & 1.46 & 5.42 \\
$p_{W}$ & $\$ /$ Mcf & 2.53 & 1.22 & 1.56 & 5.57 \\
\hline \hline \multicolumn{5}{c}{ Table 2. Descriptive statistics. }
\end{tabular}

Table 2. Descriptive statistics.

Note: $\mathrm{MMcf}=$ one million cubic feet, $\mathrm{Mcf}=$ one thousand cubic feet. GDP in annual value.

Results. We use 3SLS, a method that estimates the covariance matrix of the shocks and does not require normal distributions of the shocks for consistency. Test 1 is passed in a first 3SLS run, so we impose $\beta_{4}^{0}=0$ and $\beta_{4 \Delta}=-1$ in the final estimation. This hardly changes the estimates. As for Test 2: the correlation is -.299 with standard error .185 (corresponding to a probability of .126 under the null hypothesis). Though catch-up effects seem not to be absent, their magnitude is low.

Equation (27) is replaced by

$$
p_{y W}=\beta_{3}^{0}+\beta_{3 p} p_{y S}+\varepsilon_{y 3},
$$

where $\varepsilon_{y 3}$ represent winter shift (correlation with $\varepsilon_{y 1}$ is allowed, meaning that the shift may be partially anticipated). Tests 3, 4 and 5 are passed successfully. The estimate for the interest rate is $\widehat{r}=10 \%$, whereas there is no significant evidence of the impact of storage unit cost $(\widehat{c}$ is not significantly different from 0 ). Overall, the theory we exposed is not contradicted by the data. See Table 3. 


\begin{tabular}{ccccc}
\hline \hline Equation & Coeff. & St. Err. & $z$ & $P>|z|$ \\
\hline \hline$\Delta_{y S}=\cdots$ & & & & \\
Constant & $1.57 \times 10^{7}$ & $6.82 \times 10^{6}$ & 2.30 & .022 \\
$p_{y S}$ & $2.50 \times 10^{5}$ & $1.46 \times 10^{5}$ & 1.72 & .086 \\
$Y_{y S}$ & -35.4 & 93.2 & -0.38 & .705 \\
$T_{y S}$ & $-2.29 \times 10^{5}$ & $1.05 \times 10^{5}$ & -2.18 & .029 \\
\hline$\Delta_{y W}=\cdots$ & & & \\
Constant & $-5.51 \times 10^{6}$ & $1.78 \times 10^{6}$ & -3.08 & .002 \\
$p_{y W}$ & $2.58 \times 10^{5}$ & $1.10 \times 10^{5}$ & 2.33 & .020 \\
$Y_{y W}$ & -336 & 91.6 & -3.66 & .000 \\
$T_{y W}$ & $1.35 \times 10^{5}$ & $4.76 \times 10^{4}$ & 2.84 & .005 \\
\hline$p_{y W}=\cdots$ & \multicolumn{5}{c}{} \\
Constant & -.168 & .181 & -0.93 & .351 \\
$p_{y S}$ & 1.10 & .068 & $1.47^{*}$ & $.144^{*}$ \\
\hline \hline${ }^{*}$ Tested against 1. & \multicolumn{5}{c}{} \\
\hline \hline \multicolumn{5}{c}{ Table 3. Core equations of the seasonal storage model. }
\end{tabular}

\section{A.6 Production and imports}

We ran regressions of domestic production and net imports on the current price. The results are not stable (exclusion of a particular year or inclusion of normally irrelevant explanatory variables have an impact on the estimates) and tend to exhibit excess price elasticity (derived effect of price on demand has the wrong sign). This happens whether we include the production equations in the previous system (3SLS) or estimate them separately (OLS/2SLS). In contrast, the four core equations (25)-(28) give similar estimates with the three methods.

One obvious reason for this is that production largely depends on productive capacity, which we thus proxied with the number of active wells given by the EIA. This indicator does not account for the extreme heterogeneity between wells; nevertheless, the predicted price elasticities are now lower, indicating that we are more in line with the short term logic we put forward. Remark that the dynamics of this kind of data is extremely hard to capture in a model. ${ }^{12}$ We restricted the sample to years 1993 to 2005, the period between 1986 and 1992 having a strong influence on the estimates. See Table 4 . The small sample cannot warranty precise estimates. In accordance with economic intuition, the implied price elasticity of demand is now negative; the impact of prices on domestic production is not significant, whereas imports are price-inelastic.

Once domestic production and net import parameters are known, demand

\footnotetext{
${ }^{12}$ See the classic Balestra and Nerlove (1966) on the modeling of demand for natural gas with consideration of the stock of appliances.
} 
parameters are calculated using the accounting identity (3).

\begin{tabular}{cllll}
\hline \hline Equation & \multicolumn{1}{c}{ Coeff. } & St. Err. & $z$ & $P>|z|$ \\
\hline \hline Summer dom. prod. & & & & \\
Constant & $8.60 \times 10^{6}$ & $9.18 \times 10^{5}$ & 9.37 & .000 \\
$p_{y S}$ & $-1.40 \times 10^{5}$ & $1.27 \times 10^{5}$ & -1.10 & .280 \\
Wells & 4.59 & 3.66 & 1.25 & .217 \\
\hline Summer net imp. & & & \\
Constant & $1.05 \times 10^{6}$ & $1.44 \times 10^{5}$ & 7.29 & .000 \\
$p_{y S}$ & $2.08 \times 10^{5}$ & $4.66 \times 10^{4}$ & 4.46 & .000 \\
\hline Winter dom. prod. & & & \\
Constant & $1.08 \times 10^{7}$ & $6.47 \times 10^{5}$ & 16.71 & .000 \\
$p_{y W}$ & 9070 & $8.47 \times 10^{4}$ & 0.11 & .915 \\
Wells & -3.18 & 2.58 & -1.23 & .226 \\
\hline Winter net imp. & & & \\
Constant & $1.19 \times 10^{6}$ & $1.31 \times 10^{5}$ & 9.09 & .000 \\
$p_{y W}$ & $1.92 \times 10^{5}$ & $4.03 \times 10^{4}$ & 4.78 & .000 \\
\hline \hline & Table 4. Domestic production and imports.
\end{tabular}

